\title{
Direct interactions with commensal streptococci modify intercellular communication behaviors of Streptococcus mutans
}

\author{
Justin R. Kaspar $\mathbb{1}^{1,2} \cdot$ Kyulim Lee $\mathbb{I}^{1} \cdot$ Brook Richard $^{1} \cdot$ Alejandro R. Walker $\mathbb{D}^{1} \cdot$ Robert A. Burne $\mathbb{( I}^{1}$
}

Received: 19 May 2020 / Revised: 10 September 2020 / Accepted: 18 September 2020 / Published online: 30 September 2020

(c) The Author(s) 2020. This article is published with open access

\begin{abstract}
The formation of dental caries is a complex process that ultimately leads to damage of the tooth enamel from acids produced by microbes in attached biofilms. The bacterial interactions occurring within these biofilms between cariogenic bacteria, such as the mutans streptococci, and health-associated commensal streptococci, are thought to be critical determinants of health and disease. To better understand these interactions, a Streptococcus mutans reporter strain that actively monitors cell-cell communication via peptide signaling was cocultured with different commensal streptococci. Signaling by S. mutans, normally highly active in monoculture, was completely inhibited by several species of commensals, but only when the bacteria were in direct contact with S. mutans. We identified a novel gene expression pattern that occurred in S. mutans when cultured directly with these commensals. Finally, mutant derivatives of commensals lacking previously shown antagonistic gene products displayed wild-type levels of signal inhibition in cocultures. Collectively, these results reveal a novel pathway(s) in multiple health-associated commensal streptococci that blocks peptide signaling and induces a common contact-dependent pattern of differential gene expression in S. mutans. Understanding the molecular basis for this inhibition will assist in the rational design of new risk assessments, diagnostics, and treatments for the most pervasive oral infectious diseases.
\end{abstract}

\section{Introduction}

Bacteria within multispecies communities grow and persist in complex environments by competing over scare resources such as nutrients and physical space [1, 2]. One potential survival tactic is the synchronization of individual bacteria within a given species to coordinate their response to competitors through communication networks involving cell-cell signaling [3, 4]. This process is often referred to as quorum sensing, as coordinated changes in gene expression patterns (GEP) are observed once the signal has reached a

Supplementary information The online version of this article (https:// doi.org/10.1038/s41396-020-00789-7) contains supplementary material, which is available to authorized users.

Justin R. Kaspar

Kaspar.17@osu.edu

1 Department of Oral Biology, College of Dentistry, University of Florida, Gainesville, FL, USA

2 Division of Biosciences, College of Dentistry, Ohio State University, Columbus, OH, USA critical concentration that often correlates with the density of the bacterial population [5]. In recent years, considerable progress has been made in understanding the molecular mechanisms that govern bacterial cell-cell communication pathways, but the biology and significance of these systems have mainly been studied with monospecies cultures in reasonably well-defined conditions [6]. While this reductionist approach has yielded a wealth of information, current exploration of complex microbial populations supports the need to examine cell-cell signaling behaviors under conditions that more closely mimic the natural environment where the signaling may be of ecologic significance.

The human oral cavity is ideally suited as a model for the dissection of interspecies interactions. In the human mouth, billions of microbes belonging to over 700 independent taxa function cooperatively and/or antagonistically to shape the composition of the microbiome [7, 8]. These interactions, coupled with frequent environmental perturbations, can also disrupt microbial homeostasis; which can lead to the ecological shifts observed during development of oral diseases [9]. For example, as is the case for dental caries (tooth decay), increases in the proportions of strongly acidogenic and acid tolerant bacteria, such as the mutans streptococci, 
are observed when bacterial fermentation of dietary carbohydrates repeatedly acidifies microbial biofilms, leading to demineralization of the tooth [10-12]. Concurrently, healthassociated commensal streptococci, which are less constitutionally resistant to low $\mathrm{pH}$, decrease in proportions. Loss of these species compounds the problem as many of these commensal streptococci provide protection from caries development by metabolizing arginine via the arginine deiminase system [13, 14], which elevates the $\mathrm{pH}$ through release of ammonia. Furthermore, many commensal streptococci can directly inhibit growth and/or expression of virulence traits by mutans streptococci through multiple strategies; with the generation of hydrogen peroxide being a significant deterrent to growth of Streptococcus mutans $[15,16]$ and other oral pathogens [17]. Recently, it was shown that a novel Streptococcus strain, designated Streptococcus $\mathrm{sp}$. A12, has the ability to degrade the two primary cell-cell signal peptides of $S$. mutans, competence stimulating peptide (CSP) and $\operatorname{com} X$-inducing peptide (XIP) $[18,19]$, suggesting that inference of cell-cell communication could be an underappreciated antagonistic mechanism that contributes to caries resistance.

Gram-positive bacteria utilize short, hydrophobic peptides, sometimes termed pheromones, as signaling molecules to control a spectrum of processes, including genetic competence, sporulation and production of toxins [20]. Genetic competence, a transient phenotypic state that renders cells able to internalize extracellular DNA, has proven to be a particularly informative model to study cell-cell signaling by streptococci, with two distinct cell signaling systems present controlling competence induction in these organisms. One extracellular signaling system consists of a signal-sensing kinase on the cell surface that transduces signal perception to a cytoplasmic response regulator via phosphorylation. In streptococci, this pathway (ComCDE) has been most extensively studied in Streptococcus pneumoniae [21-23]. A second, intercellular signaling mechanism is present in other phylogenetic groups of streptococci, wherein the peptide signal is imported into the cell and is bound by a cytosolic transcriptional regulator that controls the activities of different promoters to regulate gene expression $[24,25]$. The best described example of this system is the ComRS pathway of the dental caries pathogen $S$. mutans [26]. Here, the propeptide ComS is exported by select transporters [27] and by cell lysis [28, 29]. The mature, active peptide, XIP, accumulates extracellularly [30] and can be reimported into the cell by the Opp oligopeptide permease [31]. XIP is bound by the cytosolic, Rggtype regulator ComR [32], leading to conformational changes that allow the dimeric ComR-XIP complex to activate comS transcription [24], creating a positive feedback loop for the system. The ComR-XIP complex also activates the expression of the sole alternative sigma factor in S. mutans, comX, that controls competence development through activation of multiple genes; including those for the production of a pilus that uptakes exogenous DNA and for homologous recombination of the internalized singlestranded DNA [33-35]. Other ComRS-like pairs are encoded in multiple streptococci, where the cognate small hydrophobic peptide (SHP) encoded by the comS-like gene interacts with its cognate ComR-like transcriptional regulator, although there appears that certain SHPs may interact with multiple ComR-like proteins [36, 37]. The ComRS system of $S$. mutans, however, appears highly specific for $S$. mutans and genetic competence. Of note, cytoplasmic XIP and perhaps ComS may activate the pathway absent export and reimportation [29].

Previously, we provided definitive evidence that the XIP peptide of $S$. mutans can function as an intercellular signaling molecule to mediate ComRS cell-cell signaling and activation of genetic competence [28]. These experiments were performed in monospecies cocultures containing a genetically engineered $S$. mutans "sender" strain that overproduced XIP and an S. mutans "receiver" strain that lacked comS; signaling was measured in the comS mutant using a fluorescent reporter gene ( $g f p$ ) fused to the $\operatorname{comX}$ promoter $(\mathrm{P} \operatorname{com} X)$. The sender strain efficiently activated $\operatorname{com} X$ expression in the receiver strain, both planktonically and within biofilm populations. Here, we begin to describe how ComRS signaling is impacted by the presence of commensal streptococci, a closer approximation of the complexities of interactions that occur during the maturation of dental biofilms.

\section{Results}

\section{Inhibition of cell signaling by commensal streptococci}

To study how S. mutans ComRS signaling could be impacted by the presence of a competing species, we empirically optimized a dual-species model system (Fig. 1a) in which a strain of $S$. mutans carrying the promoter regions of comS or comX (Pcoms, PcomX) fused to a codonoptimized green fluorescence protein $(g f p)$ reporter gene could be cocultured with wild-type strains of Streptococcus gordonii DL1, Streptococcus sanguinis SK150, or S. sp. A12. All experiments were performed in chemically defined medium (CDM) [38, 39] because activation of the ComRS circuit occurs spontaneously in CDM as cell density increases, with no need for addition of synthetic XIP or overexpression of the gene for the XIP precursor ( $\mathrm{comS}$ ) (Supplementary Fig. 1). CDM is also heavily buffered with phosphate, which is advantageous because ComRS signaling is optimal at neutral $\mathrm{pH}$ values [40, 41]. The buffer also 
A

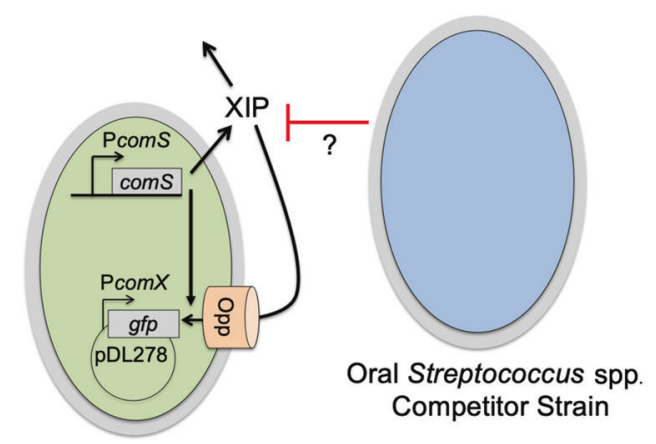

Streptococcus mutans

PcomX::gfp Reporter

D

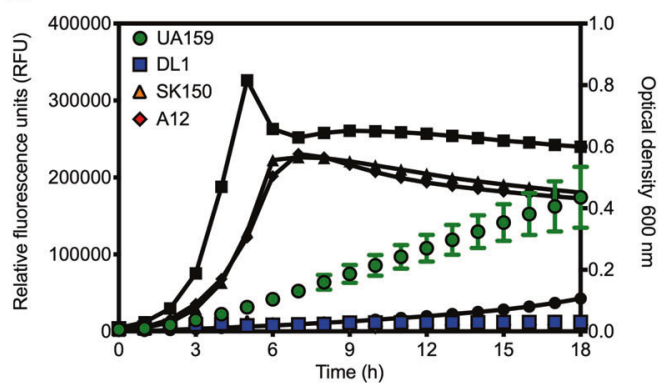

Fig. 1 Loss of $S$. mutans peptide signaling in presence of competitor. a An oral Streptococcus spp. competitor strain (blue) was cocultured in chemically defined medium (CDM) with an $S$. mutans PcomX::gfp reporter strain (green). As cell density of the reporter strain increases during growth, the XIP peptide that originates from the comS gene will be produced and accumulates extracellularly. XIP is then reimported into the cell through the Opp oligopeptide permease, binds to ComR and activates the $\operatorname{com} X$ promoter. Additionally, intracellular signaling occurs with ComS binding directly to ComR. The reporter strain harbors a plasmid, pDL278, carrying a copy of $g f p$ that is driven by the $\operatorname{com} X$ promoter $(\mathrm{P} \operatorname{com} X)$ to monitor ComRS signaling activation. b Cocultures of the $S$. mutans PcomX::gfp reporter strain grown with either $S$. mutans UA159 (control, green circles), S. gordonii DL1 (blue squares), S. sanguinis SK150 (orange triangles), or $S$. sp. A12 (red diamonds). Colored, non-connected symbols represent relative fluorescent units (RFUs) plotted on the left $y$-axis, while black,

prevents the generation of strongly acidic conditions by S. mutans, which is detrimental to the comparatively acidsensitive commensal Streptococcus spp.

When the PcomX::gfp reporter strain was cocultured with wild-type S. mutans UA159 (control), robust ComRS signaling was observed as cell density increased (Fig. 1b). However, when cocultured with a competitor Streptococcus spp., no signal from the $S$. mutans reporter could be detected above background levels; i.e., the nonspecific fluorescence generated by an $S$. mutans strain that did not
B

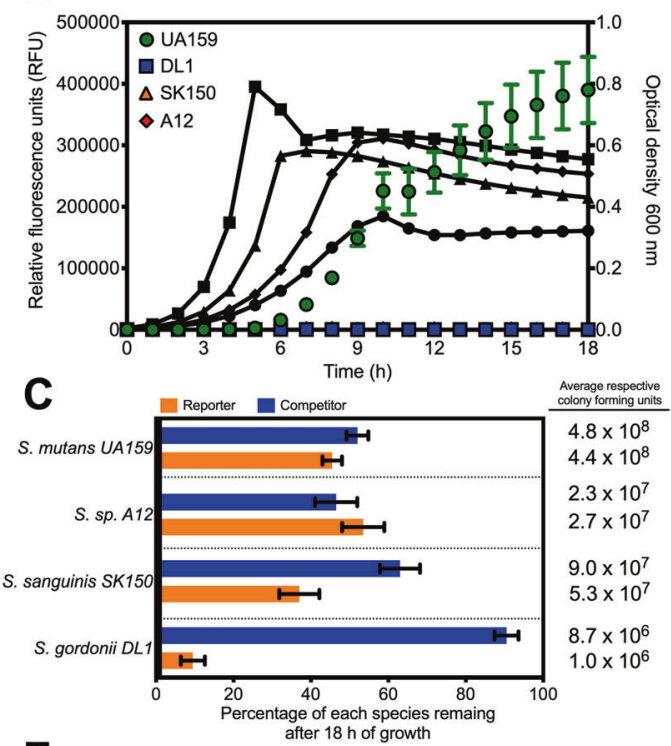

E

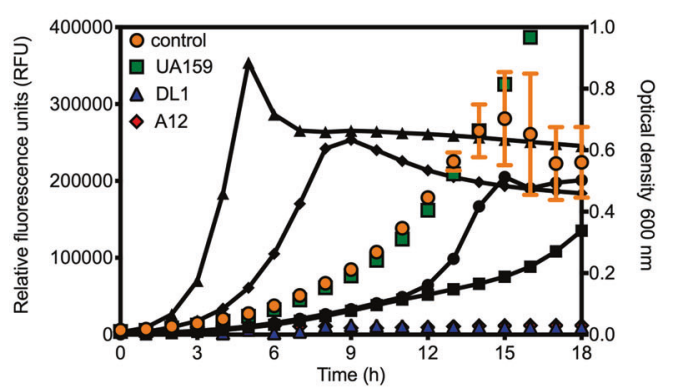

connected lines with symbols represent growth of the cocultures over the course of the experiment measured by optical density at $600 \mathrm{~nm}$ plotted on the right $y$-axis. Data are averages from three biological replicates of the experiment. c Percentage of each species remaining within the coculture after $18 \mathrm{~h}$ of monitoring, determined by colony forming unit (CFU) plating. The PcomX::gfp reporter strain is represented in the orange bars, while the competitor, listed on the left $y$-axis, is represented in blue. Average of collected CFUs is shown to the right. Data represent averages from three biological replicates of the experiment that was conducted in panel (b). d Cocultures of the $S$. mutans PcomX::gfp reporter strain in which $5 \mu \mathrm{M}$ sXIP was added prior to the start of the experiment. e Cocultures of the $S$. mutans PcomX::gfp reporter strain that contains a plasmid that overexpresses the XIP peptide precursor, ComS. Control represents the PcomX::gfp reporter that contained an empty vector only.

contain a copy of the $g f p$ gene. The lack of fluorescence in the cocultures with commensals was not due to growth inhibition of $S$. mutans as the reporter strain constituted $10 \pm 3 \%, 37 \pm 5 \%$, or $54 \pm 3 \%$ of the total colony forming units (CFUs) recovered after $18 \mathrm{~h}$ of coculturing with $S$. gordonii DL1, S. sanguinis SK150, or S. sp. A12, respectively (Fig. 1c). The quantity of $S$. mutans cells in the commensal cocultures compared favorably with the recovery of the reporter strain $(54 \pm 5 \%)$ in coculture with wildtype $S$. mutans UA159. Of note, the fact that equal 
Fig. 2 S. mutans peptide signaling in coculture biofilms. a $3 \mathrm{D}$ volume projections of imaged biofilms in the XYorientation (from the top looking down). Each biofilm contains either $S$. mutans UA159 with a constitutive $g f p$ reporter plasmid (top row), or the PcomX::gfp reporter plasmid (bottom row) that was cocultured with either $S$. mutans (control; left), $S$. gordonii DL1 (middle), or $S$. sp. A12 (right) who all constitutively produce DsRed2. To the right of each expanded color image is the black and white image capture of each individual channel: blue (top), green (middle), and red (bottom). b Zoomed image frames of Pcom $X$-active cells within cocultured biofilms with $S$. gordonii DL1. The images captured are a single $z$ plane near or at the biofilm substratum. Two different areas of the biofilm (top and bottom rows) were imaged. Each panel represents one color channel of blue (SYTO 42 stained; total cells), green (PcomX::gfp positive cells), or red ( $S$. gordonii P23::DsRed2) followed by the merged image on the far right. The top panel of (b) is the same area of biofilm shown in Movie S1.
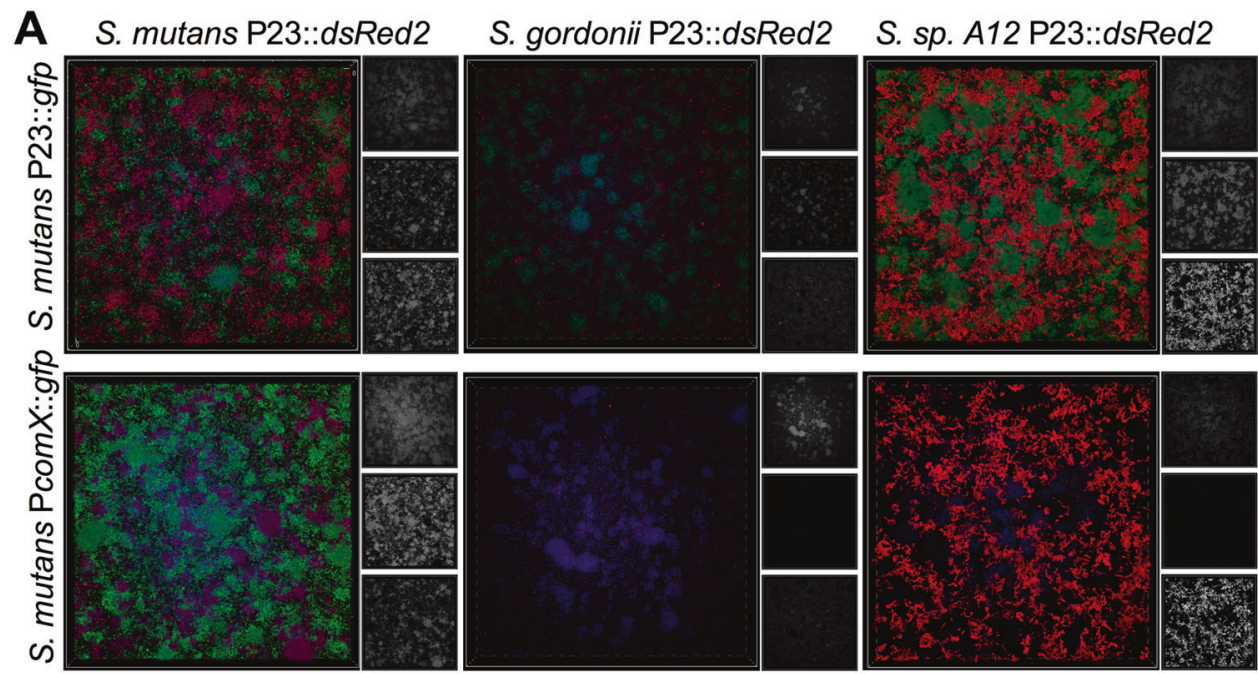

B

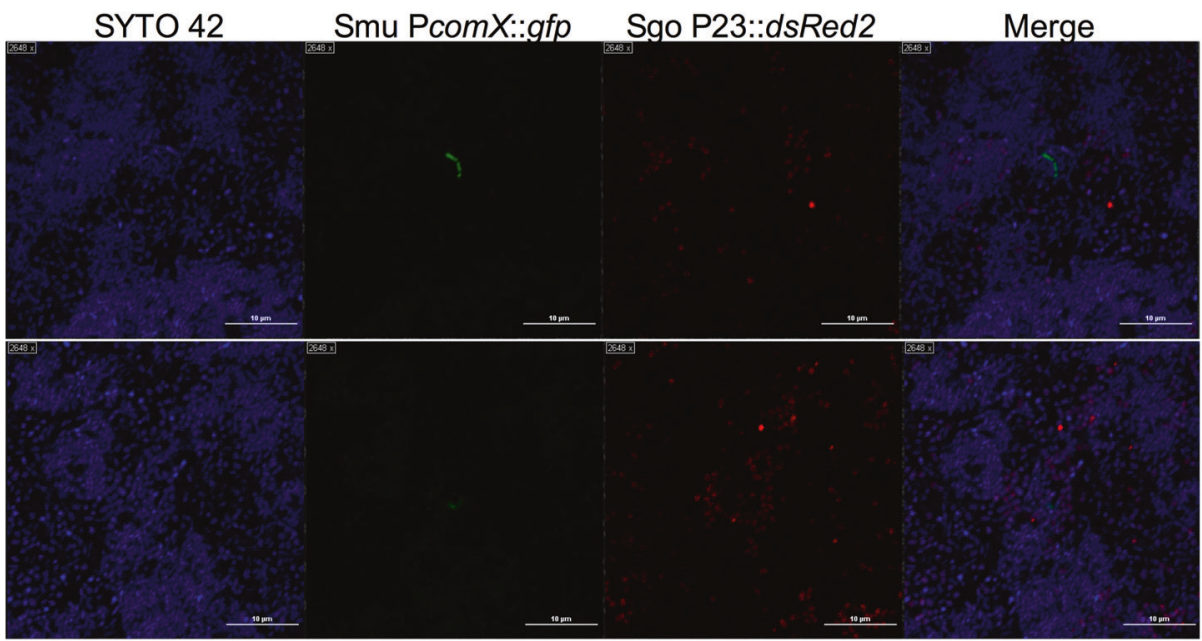

proportions of reporter and wild-type $S$. mutans were recovered from cocultures demonstrated that the presence of the GFP gene fusion did not compromise the fitness of the reporter strain, further verified by growth rate comparisons between wild-type and reporter strains (Supplementary Fig. 1).

Two strategies were implemented to try to recover active ComRS signaling by the reporter strain during cocultivation with commensal streptococci. First, synthetic XIP was added to the cocultures to a final concentration of $5 \mu \mathrm{M}$ just prior to the beginning of the fluorescence monitoring phase of the experiments, and cocultures were observed as above. No detectable fluorescence signal was recorded above background in the cocultures, with or without exogenously added XIP (Fig. 1d). Second, a plasmid encoding a copy of the XIP precursor comS under the control of a highly expressed constitutive promoter (P23) [42] was introduced into the $S$. mutans reporter strain; we previously reported that overexpression of comS could strongly activate PcomX [28]. However, no increase in GFP expression was observed in cocultures of the comS overexpressing strain with the commensals, whereas signaling was greatly enhanced when cocultured with strain UA159 as a control (Fig. 1e).

To ensure these observations were not limited to only planktonic growth conditions, we examined $S$. mutans ComRS signaling in cocultured biofilm populations. While almost all cells harboring the PcomX::gfp reporter were GFP-positive in the control biofilms (coculture of the reporter with wild-type $S$. mutans), confocal imaging of biofilms containing competitor streptococci uniformly showed that almost no $S$. mutans cells were expressing detectable GFP (Fig. 2a). However, in some frames $(0.22 \times$ $0.22 \mathrm{~mm}$ frames, $\sim 30,000 \mathrm{~S}$. mutans cells per frame), a small number of cells (1-3 cells per frame) were GFPpositive. When $3 \mathrm{D}$ renderings of these areas within the biofilm were constructed, GFP-positive cells were found close to the substratum (Fig. $2 \mathrm{~b}$ and Movie S1, same area of biofilm as top panel of Fig. 2b). Also, PcomX-active cells were not necessarily confined to distinct $S$. mutans microcolonies, and in some cases could be seen adjacent to the competitor streptococci, which carried a constitutively 
A
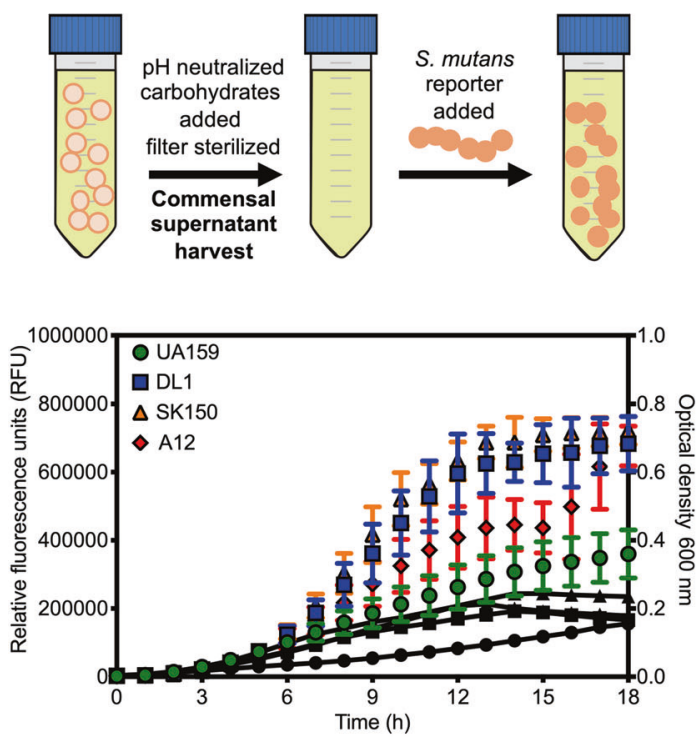

Fig. 3 Cell contact dependence in signaling inhibition. a Growth and fluorescence of $S$. mutans PcomX::gfp reporter strain in spent supernatant fluids of either $S$. mutans UA159 (control, green circles), S. gordonii DL1 (blue squares), S. sanguinis SK150 (orange triangles), or $S$. sp. A12 (red diamonds). Depiction on top shows methods used to treat supernatant fluids following harvesting and prior to reporter strain inoculation. Overnight cultures of selected strains where centrifuged, spent supernates removed, filter sterilized, the $\mathrm{pH}$ was adjusted to 7.0 and $20 \mathrm{mM}$ additional glucose was added. The PcomX::gfp reporter strain was then inoculated and monitored for $18 \mathrm{~h}$ in a Synergy

expressed red fluorescent protein (DsRed2) for their identification. To quantify the different types of cells in the biofilm populations, we physically dispersed the biofilms by sonication and analyzed the populations by flow cytometry (Supplementary Fig. 2). About 1 in 10,000 S. mutans cells counted displayed activation of PcomX within the biofilms, which was similar to the proportions of GFP-expressing cells in planktonic growth conditions (Supplemental Table 1).

\section{Commensal signaling inhibition is dependent on cell contact}

Changes in phenotypes that are observed when two different species of bacteria are cocultured can usually be induced by secreted molecules from one of the bacterial strains [1]. We suspected that molecule(s) secreted by the competitor strains are required for shutting down cell-cell signaling in S. mutans. To explore this hypothesis, we cultured the competitors individually overnight and collected the supernatant fluids after centrifugation. The supernates were then filter sterilized, $\mathrm{pH}$ adjusted from $\sim 6.3$ to 7.0 with $\mathrm{NaOH}$, and carbohydrate was added back to achieve a final concentration of added glucose to $20 \mathrm{mM}$. We then inoculated our reporter strain into the commensal supernates and
B
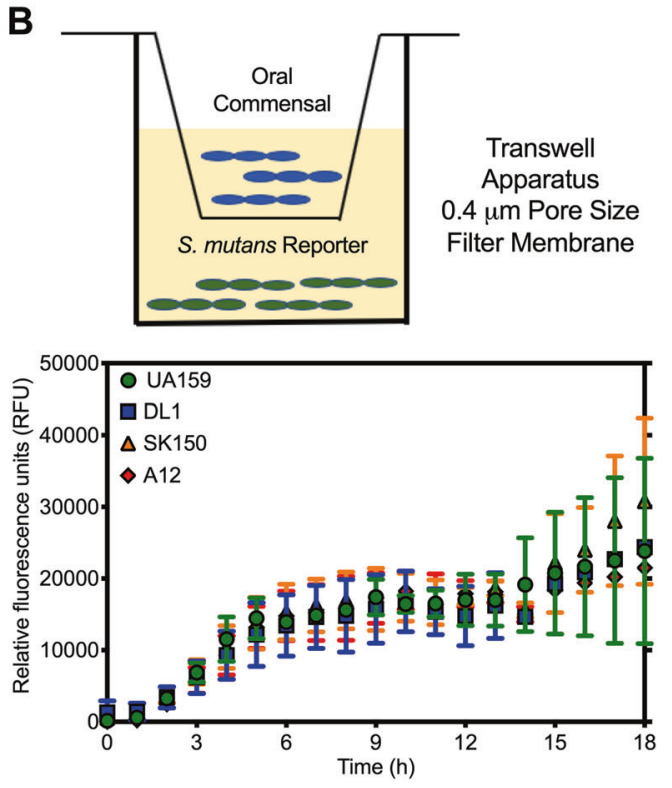

2 multimode plate reader. b Growth of cocultures in a transwell apparatus. The PcomX::gfp reporter strain was first inoculated in 0.1 $\mathrm{mL}$ of CDM medium in a 96-well microtiter plate. The transwell plate was then overlaid on top of the 96-well plate, and $0.1 \mathrm{~mL}$ of CDM inoculated with either $S$. mutans UA159 (control, green circles), $S$. gordonii DL1 (blue squares), S. sanguinis SK150 (orange triangles), or $S$. sp. A12 (red diamonds) was added to the top chamber, as shown. Cultures of the reporter strain and competitor were separated by a 0.4 $\mu \mathrm{M}$ pore size polycarbonate filter membrane. Fluorescence (RFUs) of the reporter strain was monitored for $18 \mathrm{~h}$.

monitored fluorescence activity (Fig. 3a). Surprisingly, ComRS signaling was readily observed in all supernates. In fact, reporter activity tended to be higher in the supernates of competitors compared to controls.

In another experiment to confirm these results, we grew competitor and our reporter strains together in a transwell apparatus, so that both bacterial strains shared the same growth medium, but were physically separated by $0.4 \mu \mathrm{m}$ pore size polycarbonate membrane that would allow passage of small molecule(s) between the chambers (Fig. 3b). Even in the transwell system, cell signaling was robust in cocultures containing competitor species. This result is consistent with data showing that the proximity of live commensal cells with $S$. mutans prior to signal activation is required for the signaling inhibition.

\section{Impairment of S. mutans cell signaling by oral commensals is conserved across species}

We next screened a collection of low-passage oral streptococci that had been previously genome sequenced [43] to determine whether the ability to inhibit $S$. mutans ComRS signaling was conserved across commensal species and to assess whether the presence or absence of certain genes might contribute to inhibition of peptide signaling. Ten 
different low-passage clinical isolates of $S$. gordonii, ten isolates of $S$. sanguinis, and five isolates of $S$. sp. A12related organisms [19] were cocultured with our S. mutans ComRS signaling reporter. The $S$. sp. A12-related organisms included strains classified as A12-like (A13 and BCC21), as Streptococcus australis (G1 and G2), or as Streptococcus parasanguinis (A1). Interestingly, significant production of GFP by $S$. mutans was evident when cultured with one isolate of $S$. sanguinis (BCC64) and with three isolates that were classified as A12-related (BCC21, G1 and G2) (Fig. 4a). However, these results were most likely due to the inability of these isolates to grow well within the CDM medium during the course of the experiment (Supplementary Fig. 3). In fact, after $18 \mathrm{~h}$ of monitoring, these isolates comprised $<0.01 \%$ of the total CFUs recovered. Conversely, all commensal strains that grew well in CDM (achieved an $\mathrm{OD}_{600}>0.1$ after $12 \mathrm{~h}$ as monitored using a Bioscreen system, see Supplementary Fig. 3) inhibited PcomX activation. Thus, if a commensal strain could grow in CDM, even somewhat poorly, it could completely inhibit ComRS signaling.

We also tested several genomically and phenotypically diverse isolates of $S$. mutans [44, 45], both in coculture with our PcomX::gfp reporter in the UA159 background (Supplementary Fig. 4) and against competitor Streptococcus spp., after transformation of the $S$. mutans strains with the PcomX reporter plasmid (Fig. 4b). Various levels of spontaneous activation of the PcomX::gfp reporter were observed among the different $S$. mutans strains in monocultures in CDM, consistent with recent reports showing strain-dependent differences in S. mutans peptide signaling [46]. One isolate, Smu107 (R221), had undetectable levels of GFP in monoculture in CDM alone. All others showed activity above baseline. However, when cocultured with $S$. sp. A12, ComRS signaling was inhibited to an extent similar to that observed with strain wild-type UA159. Therefore, the ability to obstruct ComRS signaling is conserved among isolates of S. gordonii, S. sanguinis, and A12-related streptococci, and inhibition by commensals is similarly conserved in genomically diverse isolates of $S$. mutans.

\section{Relatively small proportions of live commensal streptococci can inhibit signaling}

To verify that the ability of the competitor species to grow (viability) was required for inhibition of peptide signaling, we used two different treatments of the competitor species $S$. sp. A12 after it was grown to mid-exponential phase: $80{ }^{\circ} \mathrm{C}$ for $0.5 \mathrm{~h}$ in a heating block (Fig. 5a) or treatment with $4 \%$ paraformaldehyde for $1 \mathrm{~h}$ at ambient temperature (Fig. 5b). After treatment, the inactivated commensal cells were washed and resuspended in fresh CDM and then mixed with the $S$. mutans reporter strain to begin the experiment. With heat-treated cells, some ComRS signal activity was evident, but not near the levels seen with S. mutans-only controls. However, when the paraformaldehyde-treated cells were used, the competitor did not inhibit signaling and fluorescence, with levels being similar to the $S$. mutans-only control. Importantly, we determined that there was a greater number of live cells, by plating and counting CFUs, for the competitor after heat treatment, compared to paraformaldehyde fixing (Supplementary Fig. 5), which likely explains the difference in effects on PcomX activation. These results support that metabolically active and growing competitors are required for S. mutans ComRS signaling obstruction.

Based on the intermediate inhibitory effects seen with reduced proportions of a live competitor on our reporter strain, i.e. with heat-treated cells, we tested whether some minimal proportion of live competitor was required to exert effects on ComRS signaling. We utilized S. sp. A12 and varied the percentage of $S$. mutans and $S$. sp. A12 in the cocultures, after determining that the proportions of cells recovered after $18 \mathrm{~h}$ were similar to the proportions in the initial inocula (Supplementary Fig. 6). Complete inhibition of $S$. mutans ComRS signaling occurred when $S$. sp. A12 constituted $\geq 6.3 \%$ of the initial inoculum (Fig. 5 c). At 3.1 or $1.6 \%$ of $S$. sp. A12, reporter activity was detectable, but at lower levels than when no $S$. sp. A12 was present. No difference in $S$. mutans reporter activity was observed when $<1 \%$ of the inoculum was $S$. sp. A12.

Finally, we determined if timing of the introduction of the competitor commensal to the coculture affected peptide signaling behavior. In this experiment, we inoculated the reporter strain at three different dilutions $(1: 50,1: 66$, and $1: 100)$ to allow ComRS signaling to initiate at different time points during the incubation period, since activation requires that $S$. mutans attain a threshold cell density. Simultaneously, we began growing a culture of the competitor (for this experiment $S$. gordonii DL1) and control (S. mutans UA159) separate from our reporter strain. Fluorescence of the PcomX::gfp reporter was actively monitored, and at a time point $(4.5 \mathrm{~h})$ when fluorescence was fully detected (Fig. 5d), beginning to be detected (Fig. 5e) or had not yet been detected (Fig. 5f) depending on the dilution used, the competitor was added and fluorescence activity and optical density were monitored (see Supplementary Fig. 7A). Interestingly, in the case where cell-cell signaling had already been activated (Fig. 5d), or was beginning to be detected (initial stages of ComRS activation) (Fig. 5e), addition of competitor did little to dampen reporter activity. However, when competitor was added at the time point when there was no evidence yet of activation (Fig. 5f), the presence of competitor significantly impaired com gene activation, as seen at the $12 \mathrm{~h}$ time point (Supplementary Fig. 7B). 


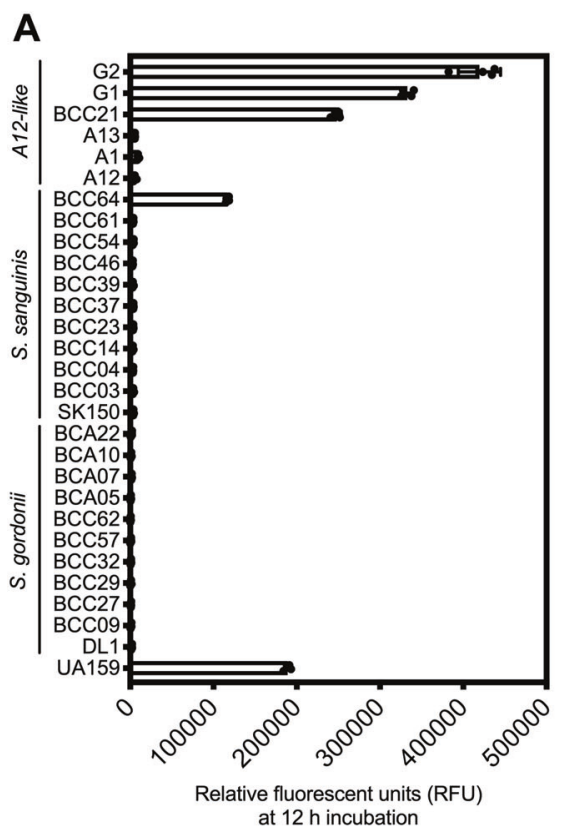

Fig. 4 Conservation of ComRS signaling antagonism across oral isolates. a Relative fluorescent units (RFUs) of the $S$. mutans PcomX:: gfp reporter strain cocultured with clinical oral isolates of either $S$. gordonii, S. sanguinis or $S$. sp. A12-like strains. Relative fluorescent units were recorded after coculture inoculation at $1: 1$ ratio and $12 \mathrm{~h}$ of incubation at $37^{\circ} \mathrm{C}$. Results from four biological replicates of the

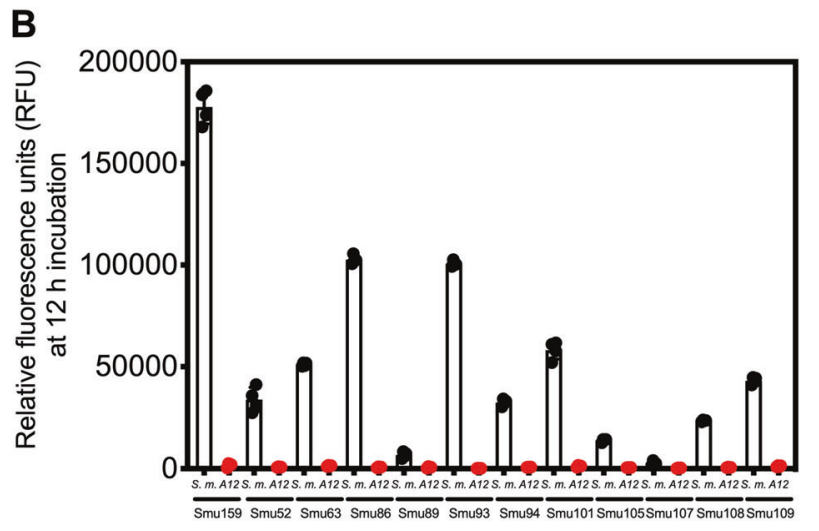

experiment are shown. b RFUs after $12 \mathrm{~h}$ of incubation of the PcomX:: $g f p$ reporter harbored in various $S$. mutans clinical isolates. The PcomX::gfp reporter strain was cocultured with either $S$. mutans UA159 (control; black dots and bars) or an oral competitor streptococci ( $S$. sp. A12, red dots and bars).
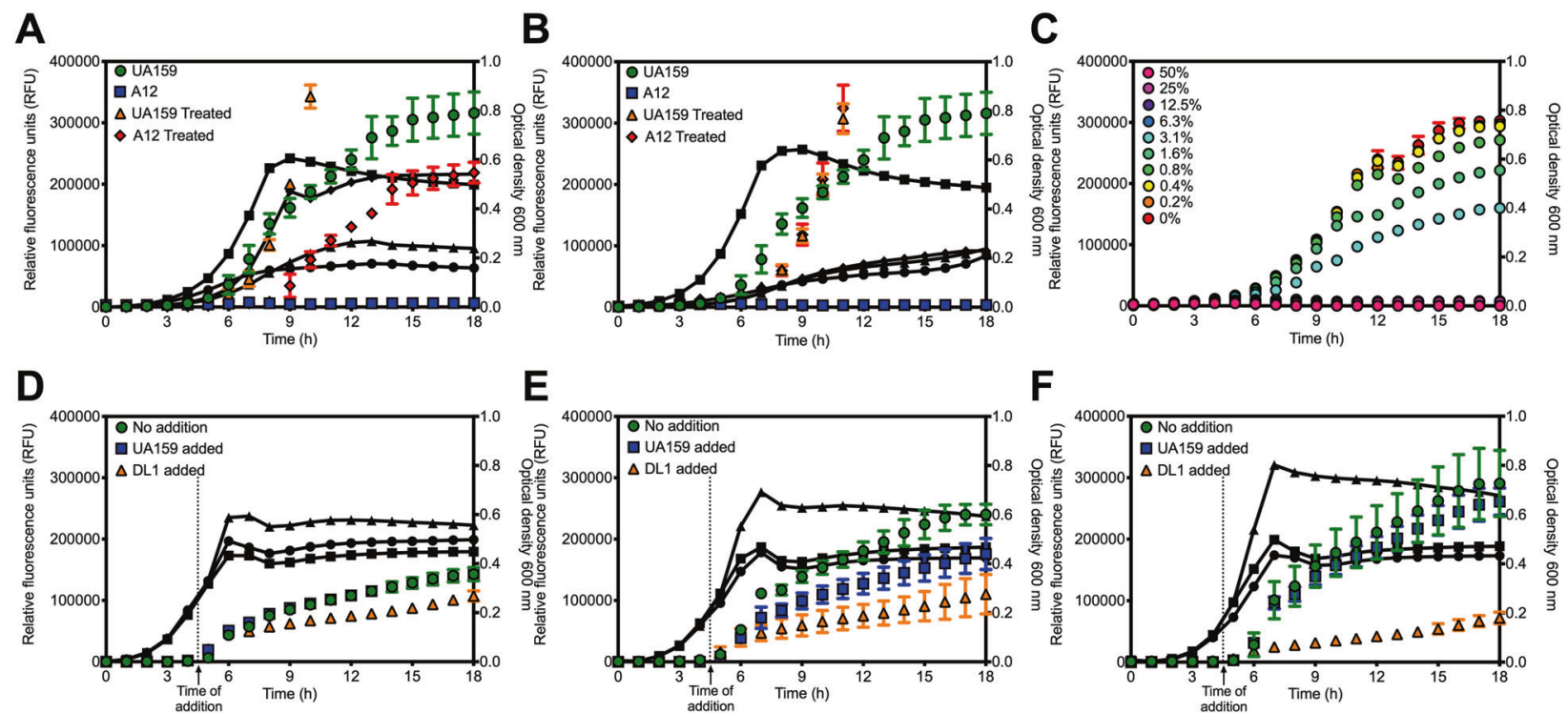

Fig. 5 Importance of oral competitor cell density in signaling inhibition. Cocultures of the $S$. mutans PcomX::gfp reporter strain with untreated or treated cells by either $\mathbf{a} 0.5 \mathrm{~h}$ heat inactivation at $80^{\circ} \mathrm{C}$ or b $1 \mathrm{~h}$ suspension in $4 \%$ paraformaldehyde. Data represent averages from three biological replicates. c Dilution of an oral competitor streptococci (S. sp. A12) in coculture with the S. mutans PcomX::gfp reporter strain. Legend (top left) refers to the amount of $S$. sp. A12 within the coculture at the time of initial inoculation. Bottom: addition of either control (UA159; blue squares) or an oral competitor streptococci (S. gordonii DL1; orange triangles) at $4.5 \mathrm{~h}$ to a growing culture of the S. mutans PcomX::gfp strain when competence activation was $\mathbf{d}$ fully detected, $\mathbf{e}$ beginning to be detected, or $\mathbf{f}$ not yet detected. See Supplementary Fig. 7 for comparisons at 4.5 and 12 h, specifically. 
Transcriptome profiling of dual-species interactions

To determine if the proximity-dependent effects on $S$. mutans of encountering oral competitor streptococci was confined to ComRS signaling and genetic competence activation, we performed transcriptome profiling by RNASeq of $S$. mutans grown in CDM under three different conditions: (1) growth in its own (S. mutans) spent supernatant fluid, (2) growth in spent supernates of a competitor (S. sp. A12; treated similarly to Fig. 3a), or (3) cocultured in fresh CDM medium directly with competitor (S. sp. A12). When comparing the growth of $S$. mutans in its own spent supernates against competitor spent supernates, we found 88 S. mutans genes differentially expressed $\left(\log _{2}\right.$ fold change $\geq(-) 1.5, \quad-\log 10 \quad p$ value $\geq 4)$, which included upregulation of the zinc transport system and several amino acid $\mathrm{ABC}$ transporters, along with downregulation of the TnSmul genomic island (Fig. 6a and Supplementary Table 2). A more substantial effect was seen when we analyzed the transcriptomes of $S$. mutans grown in direct cocultivation with $S$. sp. A12 compare to $S$. sp. A12 supernates alone (Fig. 6b and Supplementary Table 3). In this case, 140 genes were differentially expressed in $S$. mutans, including upregulation of one of the CRISPR gene clusters and, as would be expected, downregulation of the entire genetic competence regulon in cells grown directly with S. sp. A12. Principal component analysis of transcriptome data from these three conditions displayed a wide separation of the tested groups, demonstrating that there is a unique transcriptomic response by $S$. mutans when it is grown directly with a competitor, as opposed to cultivation in spent supernates of the competitor (Supplementary Fig. 8).

To determine if these transcriptomic responses were specific to competition with $S$. sp. A12 or represented a generalized response to commensal streptococci, as well as to confirm our RNA-Seq data set, we performed qRT-PCR on harvested RNA from cocultures of $S$. mutans grown with either S. sp. A12, S. gordonii DL1, or S. sanguinis SK150, or from $S$. mutans grown in monoculture. Two unique core genes of $S$. mutans [44] that were not differentially expressed in our RNA-Seq experiment, SMU.996 and Smu.1616c, were used to normalize the amount of $S$. mutans present at the time of harvest between all cocultured samples (Supplementary Table 4). In total, eight genes were probed that represented both upregulated (Fig. 6c) and downregulated (Fig. 6d) genes found during our RNA-Seq experiment. Remarkably, S. mutans displayed the same genetic response in all three cocultures with different competitor species, including upregulation of cas 3 and the gene for a secreted glucosyltransferase $(g t f C)$ required for sucrose-dependent biofilm formation $[47,48]$. Aside from a significant decrease in $\operatorname{com} X$ expression, bacteriocin gene expression was also impacted in all three cocultures, including a decrease in $\operatorname{com} E$ (bacteriocin-related response regulator) and $\operatorname{cip} B$ (ComE-regulated bacteriocin). We propose that these selected probed genes in part represent potential larger transcriptomic changes of a conserved GEP by $S$. mutans to the presence of competitors that has not been previously reported.

\section{Inhibition of cell signaling is a novel antagonism mechanism by oral streptococci}

Oral commensal streptococci, such as $S$. gordonii and $S$. sanguinis, antagonize $S$. mutans through different mechanisms, including hydrogen peroxide production $[15,16]$ and secretion of proteases that degrade signaling molecules [18, 19, 49]. To determine if these known antagonistic pathways were responsible for contactdependent inhibition of com gene activation, we cocultured our reporter strain with $S$. gordonii (Fig. 7a) or with $S$. sp. A12 (Fig. 7b) that carried deletions in known genes involved in antagonism. Specifically, for hydrogen peroxide production, we tested competitors that carried a deletion of $s p x B$, encoding pyruvate oxidase $[16,18]$. No recovery of $S$. mutans ComRS signaling was observed when cocultured with the $s p x B$ mutants, suggesting hydrogen peroxide production was not required for obstruction of signaling. To further rule out the effects of oxygen metabolism as a potential mechanism for inhibition, we grew the cocultures anaerobically, yet saw no changes in ComRS signaling inhibition (Fig. 7c). In fact, reporter actively was significantly lower in anaerobic conditions, compared to the controls. Two different peptidases of $S$. sp. A12 degrade $S$. mutans signaling molecules. Sgc (an apparent orthologue of S. gordonii Challisin (49)) has CSP degrading activity [18], whereas PcfO of A12, encoded by an apparent orthologue of pepO in multiple Streptococcus spp., can degrade S. mutans XIP [19]. However, mutation of either gene had no significant effect on ComRS signaling interference in our PcomX reporter assay. We additionally analyzed $S$. mutans gene expression via qRT-PCR with six differently expressed genes, as seen in Fig. 6, grown in coculture with $S$. sp. A12 and its mutant derivatives (Supplementary Fig. 9). We saw no significant changes in the upregulated genes among the cocultures with the $S$. sp. A12 mutants, but did see significant differences in $\operatorname{com} X$ gene expression ( 1.9-fold increase) with A12 $\Delta p c f O$ and a $~ 16$-fold increase in comE expression in the $S$. mutans coculture with A12 $\Delta s g c$, suggesting both proteases do contribute to the dampening of $S$. mutans peptide signaling, albeit not with any apparent measurable effect on PcomX induction based on the reporter assays. Finally, we also proposed that the competitors could be internalizing $S$. mutans XIP as a potential nutritional source 

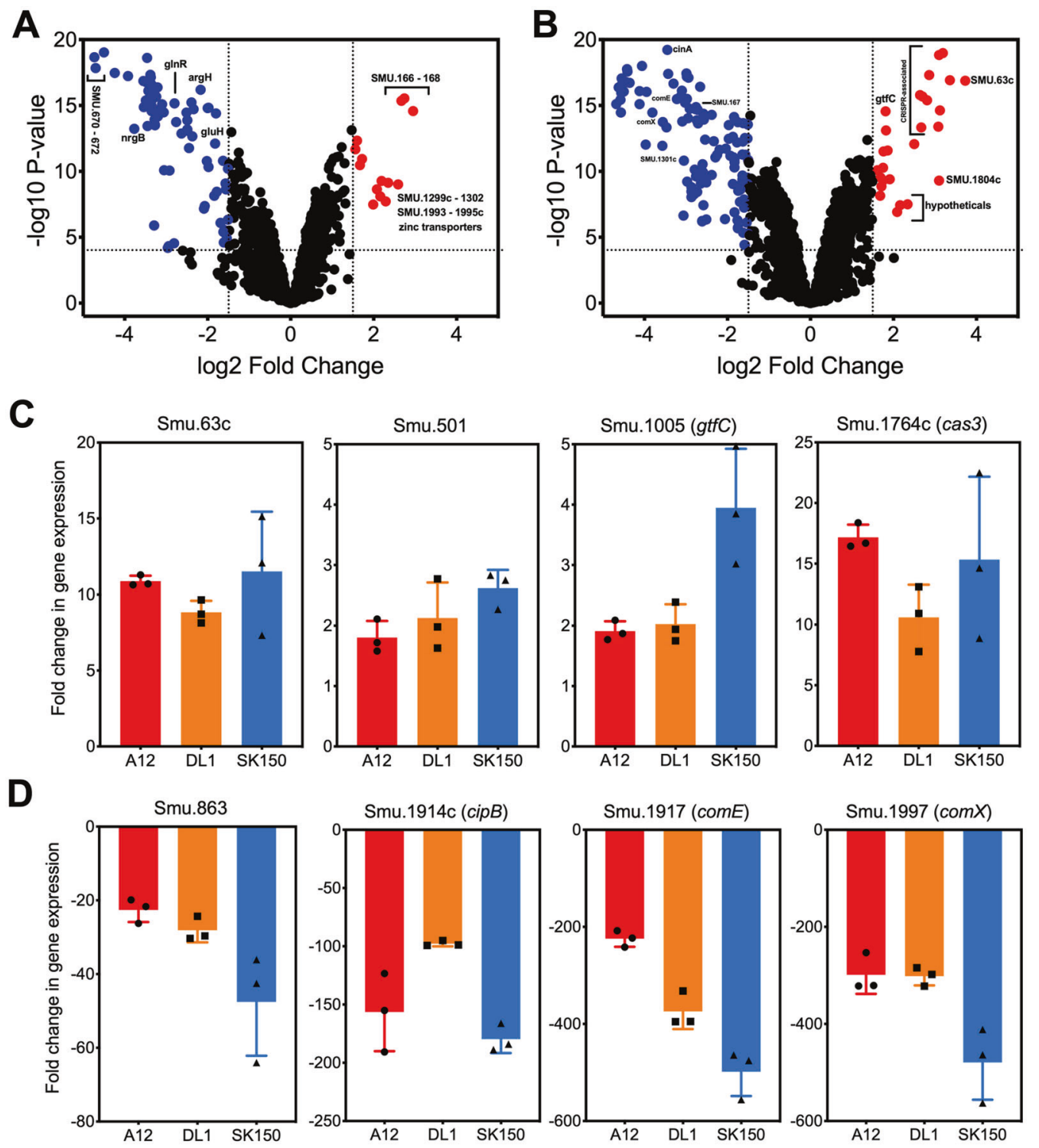

Fig. 6 Transcriptome Profiling S. mutans culture in supernates or in direct contact. Volcano plots from transcriptome analysis of a $S$. mutans UA159 cultured in $S$. sp. A12 spent supernatant fluid compared to culturing in $S$. mutans UA159 spent supernatant fluid and b $S$. mutans UA159 directly cocultured with $S$. sp. A12 compared to culturing in $S$. sp. A12 spent supernatant fluid only. Data represent three independent replicates of each condition. $\log 2$ fold changes and false discovery rates (FDR) converted to $-\log 10 p$ values were calculated from the Degust website using edgeR analysis. Genes of interest that were $\geq(-) 1.5 \log 2$ fold change and $\geq 4-\log 10 p$ values

were highlighted either in blue (downregulated, upper left quadrant) or red (upregulated, upper right quadrant) and are listed in Supplementary Tables 2 and 3, respectively. qRT-PCR confirmation of selected c upregulated or $\mathbf{d}$ downregulated genes from transcriptome analysis. Cocultures of $S$. mutans UA159 and selected competitors were grown in $\mathrm{CDM}$ medium to $\mathrm{OD}_{600}=0.5$ before harvesting for RNA extraction. Data represent fold change in gene expression compared to S. mutans UA159 monocultures. Three independent cocultures were analyzed and plotted.

in the peptide-free CDM medium. However, we saw no change when the opp homolog of $S$. gordonii (old NCBI locus tag SGO_1712) or of S. sp. A12 (ATM98_08725) was deleted. Collectively, then, we conclude that there are novel and mechanistically uncharacterized strategies used by genetically diverse commensal streptococci to impair $S$. mutans cell-cell signaling that also lead to a unique transcriptome response that is distinct from monocultures or when $S$. mutans is exposed to supernates of commensal streptococci.

\section{Discussion}

Recently our group reported that part of the arsenal deployed by $S$. sp. A12, a health-associated commensal 
Fig. 7 Selected competitor mutants still inhibit $S$. mutans peptide signaling. Cocultures of the $S$. mutans PcomX::gfp reporter strain with mutants of selected oral commensal streptococci. Comparison of relative fluorescent units (RFUs) after $12 \mathrm{~h}$ of incubation in strains of a $S$. gordonii DL1, b $S$. sp. A12, and $\mathbf{c}$ in either aerobic (black bars) or anaerobic (red bars) conditions. Data are averages from four biological replicates of the experiment. The changes between parental and selected commensal mutants are all not significant. Statistical analysis shown in (c) was completed using Student's $t$ test.
A

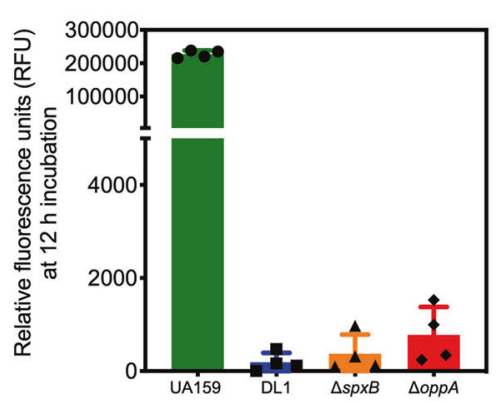

B

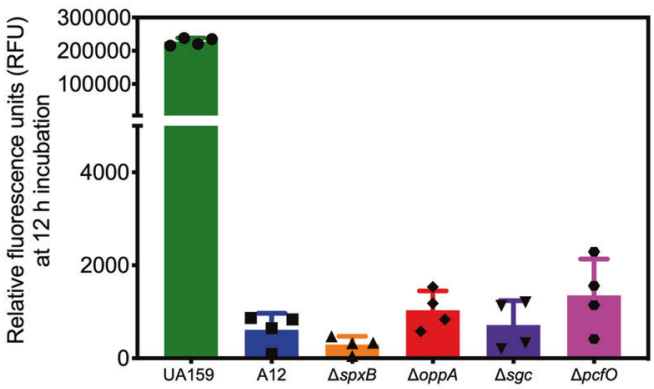

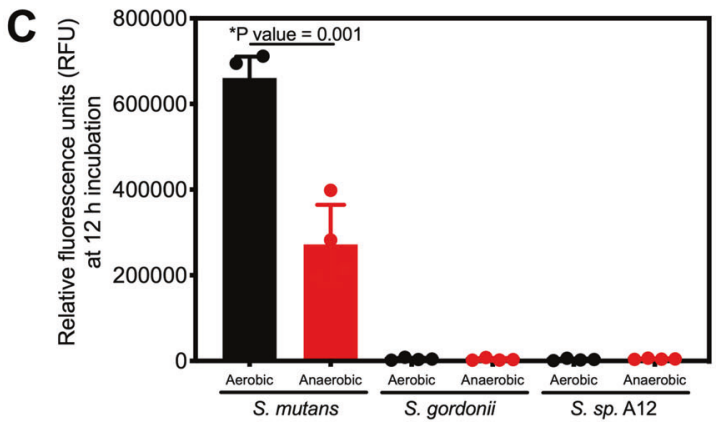

with probiotic properties, to compete with the caries pathogen $S$. mutans includes its ability to degrade peptide cell-cell signaling molecules $[18,19]$. In particular, incubation of synthetic CSP or XIP with only culture supernates alone of $S$. sp. A12 abolishes the peptides' activity via $\mathrm{Sgc}$ or PcfO, respectively $[18,19]$. We set out in this study to explore how ComRS signaling in $S$. mutans is altered during direct growth with these competitor species, conditions that should more closely mimic oral biofilms. We were immediately surprised to find that a peptide signaling system, usually displaying unimodal activation in our selected experimental conditions with cells grown in monoculture [31], was shut-off in all but a tiny fraction ( 1 in 10,000 cells) of the population by cocultivation with streptococcal isolates commonly found in supragingival plaque; inhibition was effective by both laboratory strains and by lowpassage clinical isolates. Perhaps even more intriguing was the observation that the signaling inhibition occurred only when the strains were cocultured in ways that would permit direct cell-to-cell contact, and that the inhibition did not occur when $S$. mutans was growing in spent supernates from the commensals or when commensal and pathogen were separated in a transwell apparatus but shared the same growth medium. Mutants of A12 defective in the production of proteases that may degrade signal peptides of S. mutans retained wild-type levels of inhibition in cocultures. Collectively, these results support the existence of a novel mechanism(s) that requires direct contact between the species, both in planktonic growth conditions and within biofilms. While the apparent contact-dependent mechanism(s) appears to be dominant in terms of blocking ComRS-dependent gene activation, our findings still support a role for $\mathrm{Sgc}$ and $\mathrm{PcfO}$ in the inhibition of peptide signaling, as coculturing of $S$. mutans with $s g c$ or $p c f O$ mutants of $S$. sp. A12 resulted in significant alterations in expression of $S$. mutans genes controlled by signal peptides (Supplementary Fig. 9). However, these strains most likely have minimal impact within our reporter coculture assays reported here as they displayed wild-type levels of ComRS signaling inhibition and effects seen are almost entirely driven by the novel contact-dependent mechanism.

Based on our results and the current understanding of peptide signaling and control of genetic competence, we have developed three working models for how cell signaling inhibition is affected via direct contact of commensals with S. mutans (Fig. 8), only one of which is supported by the current data. The first set of observations that is central to the model is that commensals must be alive and in contact with $S$. mutans, whether in a planktonic or biofilm state, such that the potential for direct cell-cell contact between pathogen and commensal is possible, even if only transiently. It is also relevant that $S$. mutans biofilm communities are clustered in microcolonies [50-52], with recent intact imaging of multispecies biofilms on the diseasedtooth surface displaying a "dome-like" architecture, consisting of a densely packed $S$. mutans core with commensal streptococci overlaid on top [53], similar to the microcolonies seen in our coculture biofilm data here. The second observation that is central to our models is that the addition of exogenously supplied sXIP cannot overcome the inhibition exerted by commensals cultured in direct contact. Relevant to both observations, commensals cannot 
A
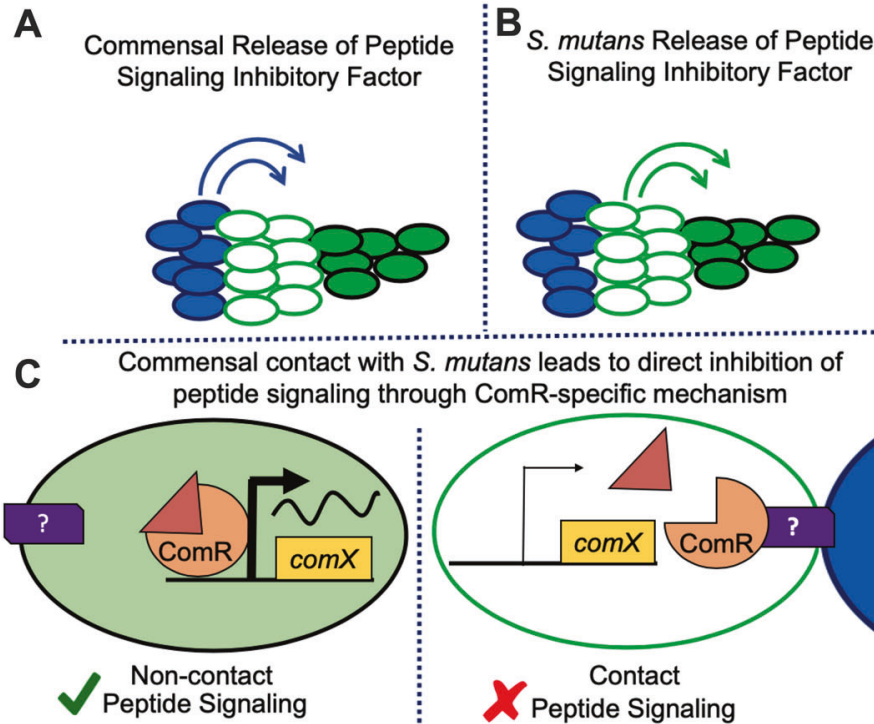

Fig. 8 Model for $S$. mutans peptide signaling inhibition. Three different models of direct contact with commensal streptococci (blue cells) leading to $S$. mutans (direct contact white cells with green outline, noncontact green cells) peptide signaling inhibition and conserved gene expression patterns. a A commensal-derived inhibitory product from the initiation of contact with $S$. mutans is secreted to modify $S$. mutans behavior and peptide sensing across the entire $S$. mutans population. b A subset of $S$. mutans that is in direct contact with commensals produces an inhibitory signal that modifies behavior

effectively block $\operatorname{com} X$ activation if the population has already initiated activation of the ComRS circuit. With those constraints, we exclude a handful of apparently simple explanations and arrive at a hypothesis that will be tested in future studies.

Based on existing literature, the simplest explanation is that the commensals all produce a factor(s) that blocks the activation of the ComRS circuit and induces a specific S. mutans GEP shown by our RNA-Seq results (Fig. 8a). Presumably, this would be a small molecule that can enter S. mutans and either complex with ComRS to shut down the ability of the XIP-ComR complex to activate its target gene (s) or lead to other transcriptomic responses resulting in similar effects. However, both the spent supernates and the transwell experiments argue that either this substance is not produced by, or is not released from the commensals, unless contact with $S$. mutans occurs. We do not favor this hypothesis because if we coculture $S$. mutans with the commensals, recover those supernates and then perform our reporter experiment in those supernates, there is no evidence of inhibition of PcomX activity (Supplementary Fig. 10). Consistent with, but not definitively supporting this logic is the observation that gene expression in the commensal ( $S$. sp. A12) is not substantially altered by cocultivation with $S$. mutans (K. Lee, manuscript in preparation); unlike $S$. mutans, which shows dramatic changes for the rest of the population, including those noncontacted $S$. mutans cells. c Transient contact between an oral commensal (blue) and $S$. mutans cell (green/green outline), prior to ComRS signaling activation, leads to posttranscriptional modifications in ComRS signaling. In the proposed mechanism shown, contact between S. mutans and commensal leads to sequestering of ComR with an unknown interaction partner, preventing ComR-XIP complex binding to the PcomX promoter and genetic competence activation.

in gene expression after direct exposure to the commensals. Thus, it does not appear that growth in the presence of S. mutans activates the expression of a specific gene product in commensals that directly causes inhibition or synthesis of an inhibitory factor. While the RNA-Seq of the commensal does not rule out potential posttranscriptional activities, the commensal gene expression data coupled with the fact that supernates from cocultures of commensals with $S$. mutans do not inhibit $\operatorname{com} X$ activation seems to exclude that a diffusible factor produced and/or released by the commensals leads to a blockage of the ComRS circuit and the observed $S$. mutans GEP.

The second model we considered was one in which contact with the commensal triggered the expression and/or release of a signal by $S$. mutans that propagates through the population to exert a negative effect on ComRS-dependent activation and inducible GEP (Fig. 8b). While this model could help explain how such a small proportion $(<2 \%)$ of commensals in cocultures could cause complete inhibition of $\operatorname{comX}$ activation, it is not consistent with the coculture supernate results mentioned above. We acknowledge that the hypothetical $S$. mutans signal molecule could be particularly labile or could work in concert with other cellassociated factors that would not be present in supernates, so we cannot completely exclude that $S$. mutans produces a signal that propagates through the population to shut off the 
ComRS circuit after contact with commensals, and retain the idea that such a factor could be necessary, but not sufficient.

The final working model is one we believe is most consistent with the data collected thus far, but it is also one that is not as common in terms of established interbacterial interactions. In particular, we posit that direct contact between the commensals and $S$. mutans, even in a relatively transient or brief fashion and as long as it is prior to activation of the ComRS circuit, induces changes in $S$. mutans that shut down the ComRS pathway (Fig. 8c). Importantly, there was no detectable alteration in the expression levels of comR in $S$. mutans cocultured with $S$. sp. A12 or other commensals, so we posit that the block occurs at the posttranscriptional, and probably at the posttranslational level. Moreover, since $\operatorname{com} X$ activation is blocked by cocultivation, the posttranslational interference likely involves either degradation of ComR, ComS, and/or XIP, or production of a molecule(s) that can complex with, for example, ComR and prevent its interaction with ComS or XIP, or inactivate the ComR-XIP complex. One such factor could be XrpA, which is encoded within the $\operatorname{com} X$ gene [54]. XrpA appears to negatively affect the ability of ComR to bind its targets [55]. However, a mutant that can produce ComX, but not $\mathrm{XrpA}$, did not display any differences from the wild-type genetic background in the coculture reporter assay used here (data not shown). Thus, a mechanism in which inhibition occurs prior to coms activation, perhaps through direct binding of a factor to ComR that renders the protein nonfunctional seems most compatible with existing data.

We have shown through our transcriptomic analyses with $S$. sp. A12, and later confirmed in a limited set of probed genes via qRT-PCR with other commensal species, that $S$. mutans may have a specific GEP in response to cocultivation with a competitor. Further transcriptomic studies with more competitors are needed to support and verify these findings. We noticed several intriguing gene candidates for further study that are highly upregulated that could serve as a mechanism to downregulate competence activation, including the cas3 CRISPR system (entire SMU.1753c-SMU.1764c region) and SMU.63c, recently shown to form amyloids that can alter biofilm architecture [56]. The identification of upregulated SMU.63c is intriguing not only from a functional aspect in its role during $S$. mutans microcolony formation, but this gene is adjacent to comRS (SMU.61) and transcribed in the opposite orientation. Use of gene-specific primers during cDNA generation rules out effects of readthrough from comRS transcription that would impact our interpretation of these results. The role these operons play, as well as others, in the fitness of $S$. mutans against competitors, as well as in potential inhibition of peptide sensing and alterations of the $S$. mutans transcriptome will be explored in future studies.
The fragility of ComRS activation is well documented as it is dampened by the presence of nonspecific peptide media constituents [31], proteases [19, 57], certain carbohydrates [57, 58], shifts in pH [40, 41], changes in (p)ppGpp levels [59], and now commensal competitors. However, genetic competence must supply some benefit to the $S$. mutans population as ComRS and competence genes are highly conserved across $100 \mathrm{~s}$ of sequenced $S$. mutans isolates $[45,46]$. The high degree of conservation of ComRS may be associated with how this peptide signaling circuit is integrated with numerous stress response systems [60]. While we have focused extensively on the output effects of peptide signaling, our documented GEP to competitors may impact other aspects of $S$. mutans virulence or fitness not extensively explored here. One example is the upregulation of glucosyltransferases $g t f B$ and $g t f C$ (higher fold change in $g t f C$ compared to $g t f B$ ), which encode the exoenzymes required for water-insoluble exopolysaccharide production during sucrose-dependent biofilm formation that would impact $S$. mutans microcolony development and spatial organization. Upregulation of $S$. mutans gtfC during growth in multispecies biofilms has been previously reported [50] and corroborates our data here. It is possible that the global transcriptomic response leads to modification of traits, such as acid production and acid tolerance, bacterial adherence, production of secreted molecules, and antimicrobial susceptibility that would modify fitness during competitive interactions. Focusing on the subset of genes and operons that show differential expression in monoculture vs. dual- or multispecies cultivation may highlight new therapeutic targets to study and understand their benefit to the organism. We must also determine how the expression of this select subset of genes is altered as the microbiome profile shifts between caries-free and caries-active states [11]. Importantly, our findings should raise awareness that studying biological systems more closely to their natural setting or in the presence of key environmental factors could dramatically enhance the understanding of how these systems function in vivo to influence health and disease.

\section{Materials and methods}

\section{Bacterial strains and growth conditions}

Strains of S. mutans and other Streptococcus spp. were cultured in brain heart infusion (BHI) broth (Difco) or CDM [38, 39] supplemented with $20 \mathrm{mM}$ glucose (planktonic plate reader experiments) or $20 \mathrm{mM}$ glucose and $5 \mathrm{mM}$ sucrose (biofilms for microscopy imaging and flow cytometry analysis). Streptococci were grown in a $5 \% \mathrm{CO}_{2}$ aerobic environment at $37^{\circ} \mathrm{C}$, unless stated otherwise. Antibiotics were added to growth media only during 
overnight growth in BHI at $1 \mathrm{mg} / \mathrm{mL}$ for both kanamycin and spectinomycin and $10 \mu \mathrm{g} / \mathrm{mL}$ for erythromycin. Strains and plasmids are listed in Supplementary Tables 5 and 6 , respectively. Cloning strategy and primers used for the opp defective strains are listed in Supplementary Table 7.

\section{Microtiter plate assays}

For monitoring of cell density (optical density at $600 \mathrm{~nm}$, $\mathrm{OD}_{600}$ ) and GFP fluorescence (relative fluorescent units, RFUs) over time, S. mutans reporter strains and respective cocultures of streptococci were processed as follows. Strains were cultured to an $\mathrm{OD}_{600}=0.5$ and then each diluted 1:100 into CDM (1:50 combined dilution) at a 1:1 inoculation ratio unless otherwise noted. In quadruplicates, cultures $(0.2 \mathrm{~mL})$ were placed in dark-sided, clear bottom, 96-well microtiter plates (Corning). For each fluorescent reporter strain, a control was used that harbored the plasmid without the $g f p$ gene to allow subtraction of background fluorescence of cells and/or media components. A mineral oil overlay was added to reduce the effects of oxygen on the bacteria and prevent evaporation. After loading, the 96-well plate was placed in a Synergy HT microtiter plate reader (BioTek). Fluorescence and optical density were measured at $30 \mathrm{~min}$ intervals using Gen5 software (BioTek). The settings to measure GFP fluorescence were as follows: excitation at $485 \mathrm{~nm}$, emission at $525 \mathrm{~nm}$; sensitivity 65 . Data readings were collected and background fluorescence or $\mathrm{OD}_{600}$ were subtracted prior to data visualization using GraphPad Prism 7 (GraphPad Software). See Supplementary information for methods regarding individual experiments.

\section{CFU determination after microtiter plate assays}

After $18 \mathrm{~h}$ of monitoring within the Synergy HT microtiter plate reader, an aliquot $(0.1 \mathrm{~mL})$ of individual cocultures was removed and added to $0.9 \mathrm{~mL}$ of phosphate-buffered saline pH 7.0 (PBS). The cell suspensions were then sonicated four times for $30 \mathrm{~s}$ in a sonicating water bath with resting in between on ice to de-chain cells. The cell suspensions were then serially diluted onto BHI agar with or without antibiotic selection to enumerate reporter cells or total cells, respectively. After $48 \mathrm{~h}$ incubation at $37^{\circ} \mathrm{C}$ in a $5 \% \mathrm{CO}_{2}$ aerobic atmosphere, CFUs were recorded. The percentage of each strain was determined by subtracting the reporter colonies (selective agar) from a total colony count (nonselective agar). Experiments were repeated at least three times.

\section{Confocal imaging of biofilm populations}

Strains of interest were grown to mid-exponential phase $\left(\mathrm{OD}_{600}=0.5\right)$. A $1 / 100$ dilution of each strain was added to $1 \mathrm{~mL}$ of CDM supplemented with $20 \mathrm{mM}$ glucose and
$7.5 \mathrm{mM}$ sucrose, and $350 \mu \mathrm{L}$ of these mixtures was used to inoculate one chamber of an ibidi $\mu$-Slide eight-well chamber slide (ibidi $\mathrm{GmbH}$; catalog number, 80826). The samples were incubated at $37^{\circ} \mathrm{C}$ in a $5 \% \mathrm{CO}_{2}$ aerobic atmosphere for $24 \mathrm{~h}$, and $1 \mu \mathrm{L}$ of blue-fluorescent $\mathrm{SYTO}^{\circledast}$ dye 42 nucleic acid stain (Invitrogen ${ }^{\mathrm{TM}}$, total bacteria) was added to each well and incubated for $15 \mathrm{~min}$ at room temperature prior to imaging. Images were acquired using a Nikon Ti2 confocal microscope and Nikon C2plus camera equipped with a Plan Apo $\lambda \times 60$ Oil Objective. For image capture, the following configuration was used: Syto45/DNA (ex 405, em 447, PMT HV 80), EGFP (ex 488, em 510, PMT HV 80), and DsRed2 (ex 561, em 785, PMT HV 110). All $\mathrm{z}$-sections were collected at $1 \mu \mathrm{m}$ intervals within a $212 \times 212 \mu \mathrm{m}$ field of view at $0.5 \mathrm{~s}$ scanning speed. At least five images were acquired from different parts of each biofilm and used for image analysis. Images shown are 3D volume views using alpha blending at an $X Y$-viewing plane.

\section{Flow cytometry}

Cocultured biofilms formed with strains inoculated in a 1:1 ratio were grown for $24 \mathrm{~h}$, harvested, washed, and resuspended in 1x PBS. Cells in $5 \mathrm{~mL}$ polystyrene round-bottom tubes were sonicated in a water bath for four intervals of $30 \mathrm{~s}$, with resting on ice. Samples were analyzed using an LSR II ${ }^{\mathrm{TM}}$ (BD Biosciences) flow cytometer. Forward and side scatter signals were set stringently to allow acquisition of single cells. In total, $5 \times 10^{4}$ cells were counted from each event, at a maximum rate of $2 \times 10^{3}$ cells per second, and each experiment was performed in triplicate. Data were acquired for unstained cells and single-color positive controls so that data collection parameters and compensation could be properly set. The data were collected using FACSDiva (BD Biosciences) and analyzed with FCS Express 6 (De Novo Software). Gating for quadrant analysis was selected by using a dot density plot with forward and side scatter, with gates set to capture the densest section of the plot. $x$ - and $y$-axis data represent logarithmic scales of fluorescent intensity (arbitrary units).

\section{Transcriptome analysis by RNA-Seq}

S. mutans UA159 and $S$. sp. A12 were grown overnight in CDM. The next day, cultures were harvested by centrifugation and spent supernatant fluid removed into a new vial. Supernatant fluids were treated by adjusting the $\mathrm{pH}$ from $\sim 6.3$ to 7.0 using $6 \mathrm{~N}$ sodium hydroxide and adding 1 $\mathrm{M}$ glucose to a final concentration of $20 \mathrm{mM}$ additional glucose. Prior to inoculation, supernates were filter sterilized with a Millex ${ }^{\oplus}$ GP $0.22 \mu \mathrm{m}$ filter unit containing a Millipore Express ${ }^{\circledR}$ polyethersulfone membrane. S. mutans UA159 was inoculated into supernatant fluids, as well as 
into direct cocultures with $S$. sp. A12 in fresh CDM medium at a 1:50 final dilution ratio (1:100 dilution of each at $\mathrm{OD}_{600 \mathrm{~nm}}=0.5$, same as microtiter plate assays). All cultures were grown to $\mathrm{OD}_{600 \mathrm{~nm}}=0.5$ before harvesting. RNA extraction, rRNA removal, library construction, and read analysis were conducted as previously described [54, 55, 61]. Briefly, $10 \mu \mathrm{g}$ of high-quality total RNA was processed using the MICROBExpress ${ }^{\mathrm{TM}}$ Bacterial mRNA Enrichment Kit (Ambion of Life Technologies, Grand Island, NY), twice, before ethanol precipitation and resuspension in $25 \mu \mathrm{L}$ of nuclease-free water. The quality of enriched mRNA samples was assessed with an Agilent Bioanalyzer (Agilent Technologies, Santa Clara, CA). cDNA libraries were generated from the enriched mRNA samples using the NEBNext ${ }^{\circledR}$ Ultra Directional RNA Library Prep Kit for Illumina (Illumina, San Diego, CA), following instructions from the supplier. Deep sequencing was performed at the University of Florida ICBR facility (Gainesville, FL). Approximately 15 million short reads were obtained for each sample. After removing adapter sequences from each short-read and trimming of the $3^{\prime}$-ends by quality scores [62], the resulting sequences were mapped onto the reference genome of strain UA159 (GenBank Accession No. AE014133) using the short-read aligner. Mapped short-read alignments were then converted into readable formats using SAMTOOLS [63]. For viewing of the mapped reads aligned to the genome, ".bam" files were uploaded into the Integrative Genomics Viewer (version 2.3.55) [64]. A ".csv" file containing raw read counts for each replicate (three) was then uploaded to Degust (http:// degust.erc.monash.edu/) and edgeR analysis performed to determine $\log 2$ fold change and false discovery rates (FDR). The $p$ value was obtained by taking the $-\log 10$ of the FDR. The data files used in this study are available from NCBI-GEO (Gene Expression Omnibus) under Accession No. GSE147421.

\section{qRT-PCR of cocultures}

Cocultures in CDM medium supplemented with $20 \mathrm{mM}$ glucose from a 1:100 initial inoculum of each respective species $\left(1: 50\right.$ total inoculum) were harvested at $\mathrm{OD}_{600}=$ 0.5. Cell lysis was achieved through mechanical disruption (bead beating) and RNA was extracted by acidic phenol phase separation. The RNA was further purified with a RNeasy minikit (QIAGEN) according to the provided protocol and in-column digestion with DNase 1 (QIAGEN). Purified RNA $(1 \mu \mathrm{g})$ was used to generate cDNA from gene-specific primers (Supplementary Table 8) using the Superscript III first-strand synthesis (Invitrogen) reverse transcription protocol. Real-time PCRs were carried out using an iCyclerQ real-time PCR detection system (Bio$\mathrm{Rad}$ ) and $\mathrm{iQSYBR}$ green supermix (Bio-Rad) according to the supplier's protocol. The expression of SMU.996 and SMU.1616c, two unique core genes of $S$. mutans, was used as an internal reference to correct for the amount of total S. mutans transcripts present at the time of harvest for each coculture (see Supplementary Table 4).

Acknowledgements Research reported in this publication was supported by the National Institute of Dental and Craniofacial Research of the National Institutes of Health under Award Numbers R01 DE013239 (JRK, ARW, and RAB), R01 DE025832 (JRK, KL, ARW, and RAB), F32 DE028469 (JRK), and F30 DE028184 (KL).

\section{Compliance with ethical standards}

Conflict of interest The authors declare that they have no conflict of interest.

Publisher's note Springer Nature remains neutral with regard to jurisdictional claims in published maps and institutional affiliations.

Open Access This article is licensed under a Creative Commons Attribution 4.0 International License, which permits use, sharing, adaptation, distribution and reproduction in any medium or format, as long as you give appropriate credit to the original author(s) and the source, provide a link to the Creative Commons license, and indicate if changes were made. The images or other third party material in this article are included in the article's Creative Commons license, unless indicated otherwise in a credit line to the material. If material is not included in the article's Creative Commons license and your intended use is not permitted by statutory regulation or exceeds the permitted use, you will need to obtain permission directly from the copyright holder. To view a copy of this license, visit http://creativecommons. org/licenses/by/4.0/.

\section{References}

1. Ghoul M, Mitri S. The ecology and evolution of microbial competition. Trends Microbiol. 2016;24:833-45.

2. Granato ET, Meiller-Legrand TA, Foster KR. The evolution and ecology of bacterial warfare. Curr Biol. 2019;29:R521-37.

3. Greenberg EP. Bacterial communication and group behavior. J Clin Invest. 2003;112:1288-90.

4. Kolenbrander PE, Andersen RN, Blehert DS, Egland PG, Foster JS, Palmer RJ. Communication among oral bacteria. Microbiol Mol Biol Rev. 2002;66:486-505.

5. Waters CM, Bassler BL. Quorum sensing: cell-to-cell communication in bacteria. Annu Rev Cell Dev Biol. 2005;21:319-46.

6. Whiteley M, Diggle SP, Greenberg EP. Progress in and promise of bacterial quorum sensing research. Nature. 2017;551:313-20.

7. Wade WG. The oral microbiome in health and disease. Pharm Res. 2013;69:137-43.

8. Jenkinson HF. Beyond the oral microbiome. Environ Microbiol. 2011;13:3077-87.

9. Bowen WH, Burne RA, Wu H, Koo H. Oral biofilms: pathogens, matrix, and polymicrobial interactions in microenvironments. Trends Microbiol. 2017;26:229-42.

10. Bowen WH. Dental caries-not just holes in teeth! A perspective. Mol Oral Microbiol. 2016;31:228-33.

11. Richards VP, Alvarez AJ, Luce AR, Bedenbaugh M, Mitchell ML, Burne RA, et al. Microbiomes of site-specific dental plaques from children with different caries status. Infect Immun. 2017;85: e00106-17. 
12. Gross EL, Leys EJ, Gasparovich SR, Firestone ND, Schwartzbaum JA, Janies DA, et al. Bacterial $16 \mathrm{~S}$ sequence analysis of severe caries in young permanent teeth. J Clin Microbiol. 2010;48:4121-8.

13. Nascimento MM, Browngardt C, Xiaohui X, Klepac-Ceraj V, Paster BJ, Burne RA. The effect of arginine on oral biofilm communities. Mol Oral Microbiol. 2014;29:45-54.

14. Huang X, Browngardt CM, Jiang M, Ahn S-J, Burne RA, Nascimento MM. Diversity in antagonistic interactions between commensal oral streptococci and Streptococcus mutans. Caries Res. 2018;52:88-101.

15. Kreth J, Merritt J, Shi W, Qi F. Competition and coexistence between Streptococcus mutans and Streptococcus sanguinis in the dental biofilm. J Bacteriol. 2005;187:7193-203.

16. Kreth J, Zhang Y, Herzberg MC. Streptococcal antagonism in oral biofilms: Streptococcus sanguinis and Streptococcus gordonii interference with Streptococcus mutans. J Bacteriol. 2008;190:4632-40.

17. Liu Y, Naha PC, Hwang G, Kim D, Huang Y, Simon-Soro A, et al. Topical ferumoxytol nanoparticles disrupt biofilms and prevent tooth decay in vivo via intrinsic catalytic activity. Nat Commun. 2018;9:2920.

18. Huang X, Palmer S, Ahn S-J, Richards VP, Williams ML, Nascimento MM, et al. Characterization of a highly arginolytic Streptococcus species that potently antagonizes Streptococcus mutans. Appl Environ Microbiol. 2016;82:2187-201.

19. Lee K, Walker AR, Chakraborty B, Kaspar JR, Nascimento MM, Burne RA. Novel probiotic mechanisms of the oral bacterium Streptococcus sp. A12 as explored with functional genomics. Appl Environ Microbiol. 2019;85:e01335-19.

20. Monnet V, Juillard V, Gardan R. Peptide conversations in grampositive bacteria. Crit Rev Microbiol. 2016;42:339-51.

21. Håvarstein LS, Coomaraswamy G, Morrison DA. An unmodified heptadecapeptide pheromone induces competence for genetic transformation in Streptococcus pneumoniae. Proc Natl Acad Sci USA. 1995;92:11140-4.

22. Håvarstein LS, Gaustad P, Nes IF, Morrison DA. Identification of the streptococcal competence-pheromone receptor. Mol Microbiol. 1996;21:863-9.

23. Straume D, Stamsås GA, Håvarstein LS. Natural transformation and genome evolution in Streptococcus pneumoniae. Infect Genet Evol. 2015;33:371-80.

24. Mashburn-Warren L, Morrison DA, Federle MJ. A novel doubletryptophan peptide pheromone controls competence in Streptococcus spp. via an Rgg regulator. Mol Microbiol. 2010;78:589-606.

25. Gardan R, Besset C, Guillot A, Gitton C, Monnet V. The oligopeptide transport system is essential for the development of natural competence in Streptococcus thermophilus strain LMD-9. J Bacteriol. 2009;191:4647-55.

26. Kaspar JR, Walker AR. Expanding the vocabulary of peptide signals in Streptococcus mutans. Front Cell Infect Microbiol. 2019;9:194.

27. Chang JC, Federle MJ. PptAB exports rgg quorum-sensing peptides in Streptococcus. PLoS ONE. 2016;11:e168461.

28. Kaspar J, Underhill SAM, Shields RC, Reyes A, Rosenzweig S, Hagen SJ, et al. Intercellular communication via the $\operatorname{com} X$-Inducing Peptide (XIP) of Streptococcus mutans. J Bacteriol. 2017;199.

29. Underhill SAM, Shields RC, Kaspar JR, Haider M, Burne RA, Hagen SJ. Intracellular signaling by the comRS system in Streptococcus mutans genetic competence. mSphere. 2018;3: e00444-18.

30. Khan R, Rukke HV, Ricomini Filho AP, Fimland G, Arntzen MØ, Thiede B, et al. Extracellular identification of a processed type II
ComR/ComS pheromone of Streptococcus mutans. J Bacteriol. 2012;194:3781-8.

31. Son M, Ahn S-J, Guo Q, Burne RA, Hagen SJ. Microfluidic study of competence regulation in Streptococcus mutans: environmental inputs modulate bimodal and unimodal expression of $\operatorname{comX}$. Mol Microbiol. 2012;86:258-72.

32. Fontaine L, Goffin P, Dubout H, Delplace B, Baulard A, LecatGuillet N, et al. Mechanism of competence activation by the ComRS signalling system in streptococci. Mol Microbiol. 2013;87:1113-32.

33. Laurenceau R, Péhau-Arnaudet G, Baconnais S, Gault J, Malosse C, Dujeancourt A, et al. A type IV pilus mediates DNA binding during natural transformation in Streptococcus pneumoniae. PLoS Pathog. 2013;9:e1003473.

34. Khan R, Rukke HV, Høvik H, Åmdal HA, Chen T, Morrison DA, et al. Comprehensive transcriptome profiles of Streptococcus mutans UA159 map core streptococcal competence genes. mSystems. 2016;1:e00038-15.

35. Johnston C, Martin B, Fichant G, Polard P, Claverys J-P. Bacterial transformation: distribution, shared mechanisms and divergent control. Nat Rev Microbiol. 2014;12:181-96.

36. Chang JC, LaSarre B, Jimenez JC, Aggarwal C, Federle MJ. Two group a streptococcal peptide pheromones act through opposing Rgg regulators to control biofilm development. PLoS Pathog. 2011;7:e1002190.

37. Jimenez JC, Federle MJ. Quorum sensing in group A Streptococcus. Front Cell Infect Microbiol. 2014;4:127.

38. Terleckyj B, Willett NP, Shockman GD. Growth of several cariogenic strains of oral streptococci in a chemically defined medium. Infect Immun. 1975;11:649-55.

39. Terleckyj B, Shockman GD. Amino acid requirements of Streptococcus mutans and other oral streptococci. Infect Immun. 1975;11:656-64

40. Guo Q, Ahn S-J, Kaspar J, Zhou X, Burne RA. Growth phase and $\mathrm{pH}$ influence peptide signaling for competence development in Streptococcus mutans. J Bacteriol. 2014;196:227-36.

41. Son M, Ghoreishi D, Ahn S-J, Burne RA, Hagen SJ. Sharply tuned $\mathrm{pH}$ response of genetic competence regulation in Streptococcus mutans: a microfluidic study of the environmental sensitivity of comX. Appl Environ Microbiol. 2015;81:5622-31.

42. Biswas I, Jha JK, Fromm N. Shuttle expression plasmids for genetic studies in Streptococcus mutans. Microbiology. 2008;154:2275-82.

43. Velsko IM, Chakraborty B, Nascimento MM, Burne RA, Richards VP. Species designations belie phenotypic and genotypic heterogeneity in oral streptococci. mSystems. 2018;3:e00158-18.

44. Cornejo OE, Lefébure T, Bitar PDP, Lang P, Richards VP, Eilertson $\mathrm{K}$, et al. Evolutionary and population genomics of the cavity causing bacteria Streptococcus mutans. Mol Biol Evol. 2013;30:881-93.

45. Palmer SR, Miller JH, Abranches J, Zeng L, Lefebure T, Richards VP, et al. Phenotypic heterogeneity of genomically-diverse isolates of Streptococcus mutans. PLoS ONE. 2013;8:e61358.

46. Ricomini Filho AP, Khan R, Åmdal HA, Petersen FC. Conserved pheromone production, response and degradation by Streptococcus mutans. Front Microbiol. 2019;10:2140.

47. Koo H, Falsetta ML, Klein MI. The exopolysaccharide matrix: a virulence determinant of cariogenic biofilm. J Dent Res. 2013;92:1065-73.

48. Bowen WH, Koo H. Biology of Streptococcus mutans-derived glucosyltransferases: role in extracellular matrix formation of cariogenic biofilms. Caries Res. 2011;45:69-86.

49. Wang B-Y, Kuramitsu HK. Interactions between oral bacteria: inhibition of Streptococcus mutans bacteriocin production by Streptococcus gordonii. Appl Environ Microbiol. 2005;71:354-62. 
50. Xiao J, Klein MI, Falsetta ML, Lu B, Delahunty CM, Yates JR, et al. The exopolysaccharide matrix modulates the interaction between 3D architecture and virulence of a mixed-species oral biofilm. PLoS Pathog. 2012;8:e1002623.

51. Koo H, Xiao J, Klein MI, Jeon JG. Exopolysaccharides produced by Streptococcus mutans glucosyltransferases modulate the establishment of microcolonies within multispecies biofilms. J Bacteriol. 2010;192:3024-32.

52. Paula AJ, Hwang G, Koo H. Dynamics of bacterial population growth in biofilms resemble spatial and structural aspects of urbanization. Nat Commun. 2020;11:1354.

53. Kim D, Koo H. Spatial design of polymicrobial oral biofilm in its native disease state. J Dent Res. 2020;99:597-603.

54. Kaspar J, Ahn S-J, Palmer SR, Choi SC, Stanhope MJ, Burne RA. A unique ORF within the comX gene of Streptococcus mutans regulates genetic competence and oxidative stress tolerance. Mol Microbiol. 2015;96:463-82.

55. Kaspar J, Shields RC, Burne RA. Competence inhibition by the XrpA peptide encoded within the comX gene of Streptococcus mutans. Mol Microbiol. 2018;109:345-64.

56. Besingi RN, Wenderska IB, Senadheera DB, Cvitkovitch DG, Long JR, Wen ZT, et al. Functional amyloids in Streptococcus mutans, their use as targets of biofilm inhibition and initial characterization of SMU_63c. Microbiology. 2017;163:488-501.
57. Underhill SAM, Shields RC, Burne RA, Hagen SJ. Carbohydrate and PepO control bimodality in competence development by Streptococcus mutans. Mol Microbiol. 2019;112:1388-402.

58. Moye ZD, Son M, Rosa-Alberty AE, Zeng L, Ahn S-J, Hagen SJ, et al. Effects of carbohydrate source on genetic competence in Streptococcus mutans. Appl Environ Microbiol. 2016;82:4821-34.

59. Kaspar J, Kim JN, Ahn S-J, Burne RA. An essential role for (p) ppGpp in the integration of stress tolerance, peptide signaling, and competence development in Streptococcus mutans. Front Microbiol. 2016;7:1162.

60. Fontaine L, Wahl A, Fléchard M, Mignolet J, Hols P. Regulation of competence for natural transformation in streptococci. Infect Genet Evol. 2015;33:343-60.

61. Zeng L, Choi SC, Danko CG, Siepel A, Stanhope MJ, Burne RA. Gene regulation by $\mathrm{CcpA}$ and catabolite repression explored by RNA-Seq in Streptococcus mutans. PLoS ONE. 2013;8:e60465.

62. Schmieder R, Edwards R. Quality control and preprocessing of metagenomic datasets. Bioinformatics. 2011;27:863-4.

63. Li H, Handsaker B, Wysoker A, Fennell T, Ruan J, Homer N, et al. The sequence alignment/map format and SAMtools. Bioinformatics. 2009;25:2078-9.

64. Robinson JT, Thorvaldsdóttir H, Winckler W, Guttman M, Lander ES, Getz G, et al. Integrative genomics viewer. Nat Biotechnol. 2011;29:24-6. 